\title{
Proteomic identification of heat shock protein 90 as a candidate target for p53 mutation reactivation by PRIMA-1 in breast cancer cells
}

\author{
Abdur Rehman 1 , Manpreet S Chahal ${ }^{2}$, Xiaoting Tang ${ }^{3}$, James E Bruce ${ }^{3}$, Yves Pommier ${ }^{4}$ and \\ Sayed S Daoud ${ }^{1,2}$
}

\author{
1Department of Pharmaceutical Sciences, Washington State University, Pullman, WA, USA \\ 2Pharmacology and Toxicology Graduate Program, Washington State University, Pullman, WA, USA \\ ${ }^{3}$ Department of Chemistry, Washington State University, Pullman, WA, USA \\ ${ }^{4}$ Laboratory of Molecular Pharmacology, Center for Cancer Research, National Cancer Institute, National Institutes of Health, Bethesda, MD, USA
}

Corresponding author: Sayed S Daoud, daoud@mail.wsu.edu

Received: 27 Jul 2004 Revisions requested: 7 Oct 2004 Revisions received: 2 May 2005 Accepted: 29 Jun 2005 Published: 27 Jul 2005

Breast Cancer Research 2005, 7:R765-R774 (DOI 10.1186/bcr1290)

This article is online at: http://breast-cancer-research.com/content/7/5/R765

(C) 2005 Rehman et al.; licensee BioMed Central Ltd.

This is an Open Access article distributed under the terms of the Creative Commons Attribution License (http://creativecommons.org/licenses/by/ 2.0), which permits unrestricted use, distribution, and reproduction in any medium, provided the original work is properly cited.

\begin{abstract}
Introduction A loss of p53 function resulting from mutation is prevalent in human cancers. Thus, restoration of p53 function to mutant p53 using small compounds has been extensively studied for cancer therapy. We previously reported that PRIMA1 (for 'p53 reactivation and induction of massive apoptosis') restored the transcriptional activity of p53 target genes in breast cancer cells with a p53 mutation. By using functional proteomics approach, we sought to identify molecular targets that are involved in the restoration of normal function to mutant p53.

Methods PRIMA-1 treated cell lysates were subjected to immunoprecipitation with DO-1 primary antibody against p53 protein, and proteins bound to p53 were separated on a denaturing gel. Bands expressed differentially between control and PRIMA-1-treated cells were then identified by matrixassisted laser desorption ionization-time-of-flight spectrometry. Protein expression in whole cell lysates and nuclear extracts were confirmed by Western blotting. The effect of combined treatment of PRIMA-1 and adriamycin in breast cancer cells was determined with a cytotoxicity assay in vitro.
\end{abstract}

Results PRIMA-1 treated cells distinctly expressed a protein band of $90 \mathrm{kDa}$ that was identified as heat shock protein 90 (Hsp90) by the analysis of the $90 \mathrm{kDa}$ band tryptic digest. Immunoblotting with isoform-specific antibodies against Hsp90 identified this band as the $\alpha$ isoform of $\mathrm{Hsp} 90$ ( $\mathrm{Hsp} 90 \alpha)$. Coimmunoprecipitation with anti-Hsp90 $\alpha$ antibody followed by immunoblotting with DO-1 confirmed that p53 and Hsp90 $\alpha$ were interacting proteins. PRIMA-1 treatment also resulted in the translocation of $\mathrm{Hsp} 90 \alpha$ to the nucleus by 8 hours. Treatment of cells with PRIMA-1 alone or in combination with adriamycin, a DNA-targeted agent, resulted in increased sensitivity of tumor cells.

Conclusion The studies demonstrate that PRIMA-1 restores the p53-Hsp90 $\alpha$ interaction, enhances the translocation of the p53Hsp $90 \alpha$ complex and reactivates p53 transcriptional activity. Our preliminary evidence also suggests that PRIMA-1 could be considered in combination therapy with DNA-targeted agents for the treatment of breast cancer, especially for tumors with aberrant p53 function.

\section{Introduction}

Many clinical studies have shown that mutations in p53 are a strong predictor of relapse and are associated with resistance to several therapeutic regimens [1,2]. Studies in our laboratories and others, for example, showed that mutations in $p 53$ in human tumor cells were correlated with decreased sensitivity to DNA-damaging agents [3-6]. An improved understanding of the relationship between $p 53$ and chemosensitivity might therefore lay the groundwork for new cancer therapies. To understand this relationship better, we recently used a

$\overline{\mathrm{DAPI}}=4$ 4,6-diamidino-2-phenylindole; $\mathrm{Hsp} 90 \alpha=$ heat shock protein $90, \alpha$ isoform; Hsp90 $\beta=$ heat shock protein $90, \beta$ isoform; MALDI-TOF $=$ matrixassisted laser desorption ionization-time-of-flight; NE = nuclear extracts; NLS = nuclear localization signal; PBS = phosphate-buffered saline; PFT $\alpha$ $=$ pifithrin- $\alpha$; WCE $=$ whole cell extracts. 
pharmacogenomic approach with complementary DNA microarrays to characterize gene expression profiles of cells containing wild-type $\mathrm{p} 53\left(\mathrm{p} 53^{+/+}\right)$and those containing an isogenic p53 knockout counterpart $\left(p 53^{-\mu}\right)$ after treatment with topotecan, a specific topoisomerase I inhibitor and a DNA-targeted agent [7]. About $10 \%$ of the transcripts detected were differentially expressed in the $p 53^{+/+}$cells in response to topotecan, whereas only $1 \%$ of the transcripts changed in the $p 53^{-\%}$ cells [7]. These data clearly showed the broad effect of p53 on the transcriptional response to DNA damage, which can lead to growth arrest or apoptosis.

Given that $p 53$ is the most commonly mutated gene in human cancers and that more than $50 \%$ of breast tumors are defective in $p 53$ [8-10], extensive research efforts are centered on restoring normal function to mutant $\mathrm{p} 53$ to promote tumor suppression. This effort includes the use of modifying peptides [11,12], antisense oligonucleotides [13] and small molecules $[14,15]$. Unfortunately, the problem of in vivo delivery and lack of selectivity to tumor cells has limited the practical application of most of these efforts. Recently, PRIMA-1 has emerged from an in vitro screen of small molecules that reactivate the transcriptional activity of mutant p53 [16]. PRIMA-1 has the capability of restoring the transcriptional transactivation function to mutant p53 in vitro and in vivo with subsequent tumor regression. PRIMA-1 also has the ability to trigger apoptosis in tumor cells as a function of its mutant p53 reactivation response [17]. We reported recently [18] that PRIMA-1 (in a effect dependent on both dose and time) restored the transcriptional activity of $p 53$ target genes such as $p 21$ Waf1/cip 1 in breast cancer cells possessing a $p 53$ mutation. However, the exact molecular mechanisms for mutant $\mathrm{p} 53$ reactivation by PRIMA1 are not yet determined. A direct interaction between PRIMA1 and p53 has not yet been demonstrated. It is possible that PRIMA-1 affects cellular chaperones, resulting in the refolding of mutant p53. Alternatively, PRIMA-1 may block complex formation between mutant $p 53$ and $p 73$, leading to the release of active $p 73$, which triggers proapoptotic target genes [15]. To identify the possible molecular candidates of mutant p53 reactivation by PRIMA-1 in breast tumor cells, in this study we used tools available for a functional proteomics approach.

Our study indicates that the restoration of the transcriptional transactivation of $p 53$ target genes such as p21Waf1/cip 1 is dependent on p53 and that the $\alpha$ isoform of heat shock protein $90(\mathrm{Hsp} 90 \alpha)$ is associated with mutant p53 reactivation by PRIMA-1. As a result of refolding of mutant $\mathrm{p} 53$ by $\mathrm{Hsp} 90$, we show that both p53 and $\mathrm{Hsp} 90 \alpha$ are translocated to the nucleus of the tumor cells for the activation of p53 target genes. The use of PRIMA-1 to reactivate mutant p53 may therefore be considered further as an approach for adjuvant chemotherapy in the treatment of breast tumors, especially in cancers with aberrant $p 53$ function.

\section{Materials and methods Drugs and materials}

PRIMA-1 (NSC-281668) was obtained from the Drug Synthesis and Chemistry Branch, National Cancer Institute (Bethesda, MD); pifithrin- $\alpha$ (PFT $\alpha$ ) and doxorubicin (adriamycin hydrochloride) were purchased from Biomol Research Inc. (Plymouth Meeting, PA). Primary antibodies against p53 and p21 were purchased from Santa Cruz Biotechnology (Santa Cruz, CA); Hsp 90 primary antibodies were from Stressgen (Victoria, BC, Canada). The goat anti-mouse, anti-rat and antirabbit secondary antibodies labeled with IRDye ${ }^{\mathrm{TM}} 38$ were purchased from LI-COR, Inc. Biosciences (Lincoln, NE) or with Alex680 from Molecular Probes, Inc. (Eugene, OR). All other chemicals were of reagent grade.

\section{Cell and culture conditions}

The human MCF-7 breast carcinoma cells ( $p 53^{+/+}$), MDA-MB231 and $\mathrm{Gl}-101 \mathrm{~A}$ ( $p 53$ mutant) were routinely maintained in monolayer cultures in RPMI-1640 medium (Invitrogen, Inc., Carlsbad, CA) supplemented with 10\% fetal bovine serum (Hyclone, Logan, UT) as reported previously [3]. As we reported previously [18], p53 protein in Gl-101A cells contains mutations at $\mathrm{Y} 236 \mathrm{C}, \mathrm{A} 278 \mathrm{P}$ and $\mathrm{R} 72 \mathrm{P}$, whereas $\mathrm{p} 53$ protein in MDA-231 cells contains mutations at A278P, R280K and M385T. Exponentially growing cultures at $80 \%$ confluence were used in all experiments. For cytotoxicity assays, cells from exponentially growing cultures were plated in 24-well tissue culture plates in RPMl-1640 medium plus $10 \%$ fetal calf serum at about $10^{4}$ cells per well, and the $\mathrm{IC}_{50}$ doses of PRIMA-1 in MDA-231 and Gl-101A cells were determined as reported previously [18]. For drug combination studies, we used $100 \mu \mathrm{M}$ PRIMA-1 and $0.2 \mu \mathrm{M}$ adriamycin. Both cell lines were treated with the following drug sequence: $A 3$, cells were treated with adriamycin for 3 hours; A24, cells were treated with adriamycin for 24 hours; P24, cells were treated with PRIMA-1 for 24 hours; AP24, cells were treated with both adriamycin and PRIMA-1; and A3P24, cells were treated with adriamycin for 3 hours followed by the removal of adriamycincontaining medium, washing with fresh medium and then incubation with PRIMA-1 for 24 hours. Each treatment was performed in quadruplicate wells in two independent experiments. The wells were washed twice with prewarmed medium, followed by the addition of $2 \mathrm{ml}$ of drug-free medium. The plates were then incubated for a further 3 days. The surviving fraction of cells was determined with the crystal violet assay, as reported previously [19]. The precision of this method with quadruplicate determinations is $10 \%$ (SD). The data were analyzed with Student's two-tailed $t$-test; $P<0.01$ was considered statistically significant.

\section{Immunoblotting and immunoprecipitation}

Cells were incubated with 0 or $100 \mu \mathrm{M}$ PRIMA-1 for 0, 2, 4 or 8 hours, then washed twice with PBS ( $\mathrm{pH} \mathrm{7.4)} \mathrm{and} \mathrm{harvested.}$ Harvested cells were either used to prepare whole cell lysates or for subcellular fractionation studies. Cell lysates were 
Figure 1

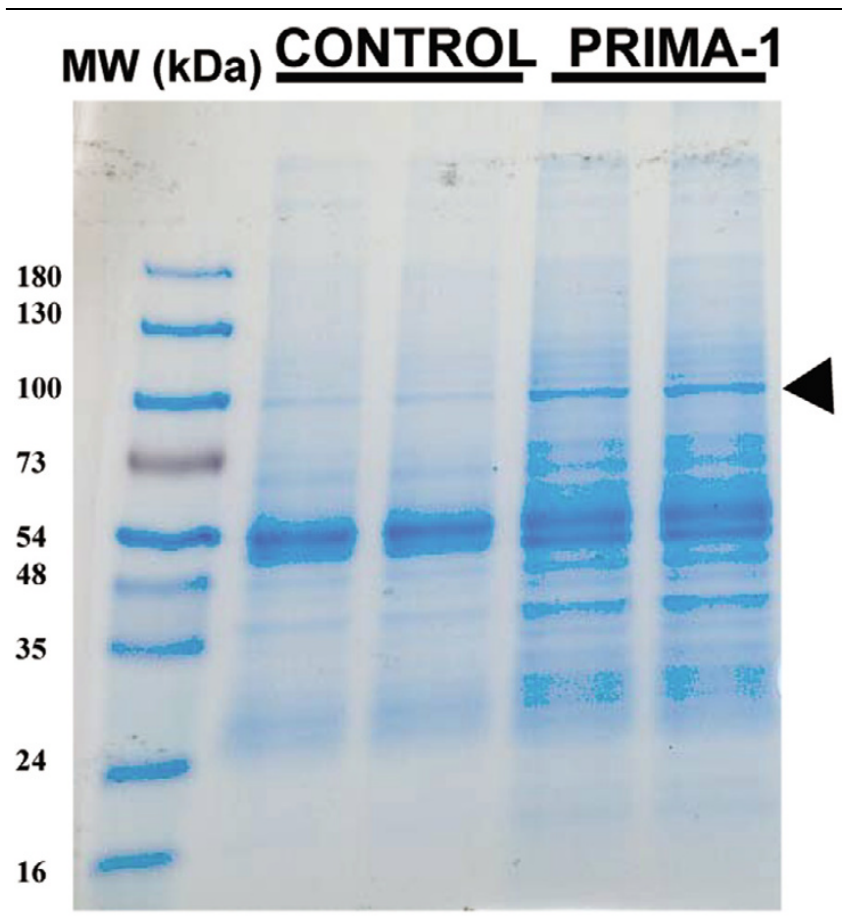

Coomassie blue-stained gel of proteins co-immunoprecipitated with DO-1 primary antibody from MDA-MB-231 cells. Cleared cell lysates were immunoprecipitated with DO-1 primary antibody directed against p53, washed, and resolved by SDS-PAGE (4 to $20 \%$ polyacrylamide). Two independent co-immunoprecipitated samples from untreated control (-) and cells treated for 4 hours with $100 \mu \mathrm{M}$ PRIMA-1 (+) were loaded. The gels were stained with Coomassie blue. Molecular masses of protein size markers are indicated (MW). The arrowhead indicates the band of stained proteins excised for enzymatic digestion by trypsin and subsequent mass fingerprinting with matrix-assisted laser desorption ionization-time-of-flight mass spectrometry.

prepared as described previously [7]. For immunoblotting, 20 $\mu \mathrm{g}$ protein samples were separated by SDS-PAGE (4 to $20 \%$ polyacrylamide gradient gel) and transferred on nitrocellulose (Millipore, Bedford, MA). The membrane was developed in accordance with a protocol provided by LI-COR, Inc. Biosciences using anti- $\beta$-actin, anti-p53 and anti-p21 primary antibodies (Santa Cruz Biotechnology) or anti-Hsp90 $\alpha$ and antiHsp90 $\beta$ primary antibodies (Stressgen). The goat anti-mouse, anti-rat and anti-rabbit secondary antibodies labeled with IRDye $^{\mathrm{TM}} 38$ (ex/em: 774/800 nm; LI-COR) or with Alexafluor ${ }^{\circledR}$ 680 (ex/em: 680/707 nm; Molecular Probes) were used. The reactive bands were revealed and detected with the Odyssey $^{\mathrm{TM}}$ Infrared Imaging System (LI-COR, Inc.).

For immunoprecipitation studies, $10^{7}$ MDA-MB-231 or Gl$101 \mathrm{~A}$ cell cultures were grown in T-150 tissue culture flasks. Cultures were treated with $100 \mu \mathrm{M}$ PRIMA-1 for 4 hours. Cleared cell lysates (total $1 \mathrm{mg}$ of protein) were immunoprecipitated either with $5 \mu \mathrm{g}$ of DO-1 anti-p53 monoclonal antibody or $5 \mu \mathrm{g}$ of anti-Hsp $90 \alpha$ monoclonal antibody in a coimmunoprecipitation assay in accordance with the protocol provided by eBiosciences, Inc. (San Diego, CA) using Protein A or G-plus agarose beads (Santa Cruz Biotechnology). After SDS-PAGE (4 to $20 \%$ polyacrylamide), gels were either stained with Coomassie blue (Bio-Rad, Inc., Hercules, CA) or subjected to immunoblotting.

\section{In-gel enzymatic digestion and mass spectrometry}

The protein bands were excised from the one-dimensional Coomassie blue-stained polyacrylamide gel shown in Fig. 1. After reduction and alkylation the protein bands were dehydrated in acetonitrile and dried. The bands were digested in the gel with an excess of sequencing-grade trypsin (Promega, Madison, WI). The digestion was performed overnight at $37^{\circ} \mathrm{C}$. The resulting tryptic peptides were extracted from the gels, then desalted and concentrated with $\mathrm{C}_{18}$ ziptip (Millipore) before spotting for matrix-assisted laser desorption ionization-time-of-flight (MALDI-TOF) analysis.

An OmniFlex MALDI-TOF mass spectrometer (Bruker Daltonics, Billerica, MA) was used for peptide mass fingerprinting. Desalted peptide solution $(1 \mu \mathrm{l})$ was mixed with $1 \mu \mathrm{l}$ of matrix solution ( $\alpha$-cyano-4-hydroxycinnamic acid in $0.1 \%$ trifluoroacetic acid and 50\% acetonitrile) and was then spotted directly on the MALDI target. All data used for protein identification and calibration were acquired in reflectron mode and averaged for 100 shots. These studies employed external mass calibration and used angiotensin I, corticotropin (ACTH) clip (1 to 17) and ACTH clip (18 to 39) peptides as calibrants. After spectral acquisition, the peak $\mathrm{m} / \mathrm{z}$ values were extracted and used to search the Swiss Protein Database with the ProFound program [20] search engine. The database search was performed with an implementation of the following search parameters: taxonomy (Homo sapiens), enzyme (trypsin), missing cleavage, mass tolerance (0.24 Da), modification (carbamidomethyl for cysteine and oxidation for methionine) and database (NCBRnr).

\section{Subcellular fractionation and immunocytochemistry}

To determine the nuclear translocation of p53 and $\mathrm{Hsp} 90 \alpha$, cells treated with PRIMA-1 were subjected to nuclear isolation with the FOCUS cytoplasmic and nuclear protein extraction kit (Geno Technology, Inc., St. Louis, MO) in accordance with the manufacturer's instructions. A fraction of the isolated nuclear pellet was fixed in 4\% paraformaldehyde in $1 \times$ PBS to determine the intactness of nuclei by staining with 4',6-diamidino-2phenylindole (DAPI). Fixed nuclei were mounted on SuperFrost-plus slides (Fisher Scientific, Pittsburgh, PA) with Prolong Gold antifade reagent with DAPI (Molecular Probes, Invitrogen Detection Technologies, Carlsbad, CA). Our nuclear preparation contained $99 \%$ intact nuclei. To determine the expression of $\mathrm{p53}$, and Hsp90s in intact nuclear fractions, the nuclear pellet was lysed into $1 \times$ SDS sample buffer and subjected to denaturing gel electrophoresis followed by immunoblotting as described above. 
To confirm translocation of proteins into the nucleus, nuclear fractions were subjected to immunostaining for p53 and Hsp90 $\alpha$. Immunocytochemistry was performed in accordance with a previously described protocol, with modifications [21]. In brief, fixed nuclear fractions were suspended in antibody buffer (0.1 M PBS, pH 7.4, containing 0.1\% Triton X-100) and incubated overnight at $4^{\circ} \mathrm{C}$ with mouse monoclonal anti-p53 (DO-1) and rat monoclonal anti-Hsp90 $\alpha$ antibody at 50:1 dilution. In addition, all appropriate negative controls without the primary antibodies were run in parallel. Unbound antibodies were removed by centrifuging nuclear preparations at $800 \mathrm{~g}$ for $3 \mathrm{~min}$ at room temperature $\left(22-24^{\circ} \mathrm{C}\right)$ followed by three subsequent 5 min washes with shaking (300 r.p.m.) in antibody incubating buffer at room temperature. Next, the bound primary antibody was detected by using species-specific secondary antibody conjugated with different fluorescent dyes at 100:1 dilution in antibody incubation buffer at room temperature for 1 hour. The mouse IgG secondary antibody conjugated with Oregon green was used to detect mouse monoclonal antibody against p53 (DO-1) and the rat IgG secondary antibody conjugated with Texas red was used to detect rat monoclonal antibody against Hsp90 $\alpha$ (Molecular Probes, Invitrogen Detection Technologies). The unbound secondary antibody was removed by using three washes as described earlier for primary antibody. After three washes, nuclear fractions were diluted in antibody incubating buffer without Triton X-100 and spread onto a SuperFrost-plus slides. The air-dried slides were then coverslipped with medium containing the nuclear stain DAPI, as before. The immunofluorescence for DAPI, Texas Red and Oregon green was detected with an Axioplan 2 epifluorescent microscope (Zeiss, Thornwood, NY) equipped with appropriate filters. Individual nuclei were visualized at $\times 20$ magnification.

\section{Results and discussion Inhibition of transcriptional reactivation function of p53 with PFT $\alpha$}

We previously reported that PRIMA-1 restored the transcriptional activity of p53 target genes, such as p21Waf1/cip1, in breast cancer cells [18]. The IC ${ }_{50}$ values for PRIMA-1 in MDA231, Gl-101A and MCF-7 cells were determined as 141, 51 and $122 \mu \mathrm{M}$, respectively. We selected p21Waf1/cip 1 as a marker for measuring the extent of the transcriptional reactivation of p53 by PRIMA-1 at both mRNA and protein levels, because the promoter of the $p 21$ gene exhibits high occupancy to wild-type $\mathrm{p} 53$ protein on its $p 53$ binding sites, in vivo; it is therefore considered a benchmark for p53-dependent genes [22]. However, p21 Waf1/cip1 can also be transcriptionally regulated by p53-independent mechanisms $[23,24]$. To determine whether the expression of $\mathrm{p} 21^{\text {Waf1/cip } 1}$ is dependent on the restored transcriptional function of $\mathrm{p} 53$, cells were treated with PRIMA-1 in the presence and in the absence of PFT $\alpha$. PFT $\alpha$ is a small molecule that was isolated for its ability to block p53-dependent transcriptional activation [25]. As shown in Fig. 2, treatment of Gl-101A cells (mut p53) with
Figure 2
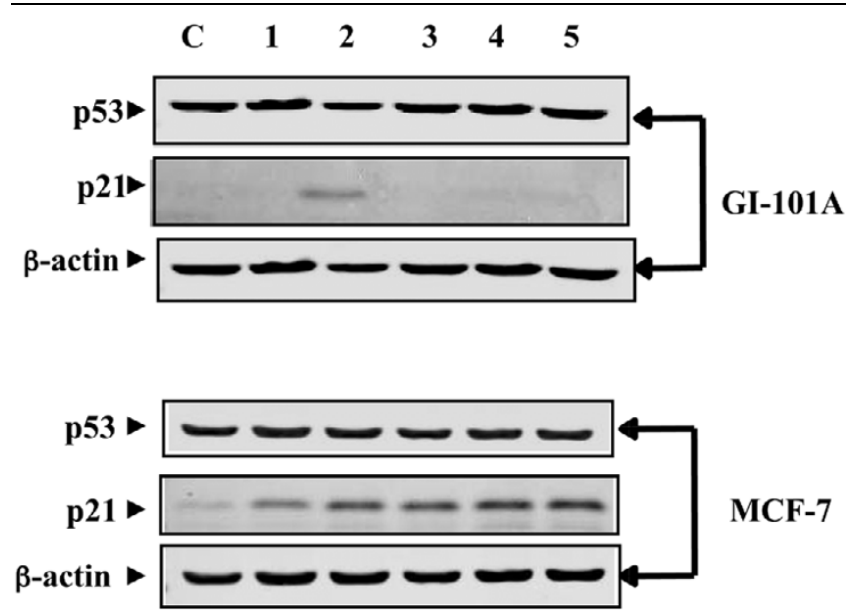

Inhibition of PRIMA-1 mediated transcriptional reactivation function of p53 with pifithrin- $\alpha$ (PFT $\alpha$ ). MCF-7 (p53/++) and Gl-101A (mut p53) cells were treated with $100 \mu \mathrm{M}$ PRIMA-1 for 2,4 and 8 hours (lanes 1 , 2 and 3, respectively). Cells were treated with $20 \mu \mathrm{M}$ PFT $\alpha$ for 6 hours (lane 4) or with $20 \mu \mathrm{M}$ PFT $\alpha$ for 2 hours followed by PRIMA-1 for 4 hours (lane 5). $20 \mu \mathrm{g}$ of protein samples of cell lysates were separated by SDS-PAGE ( 4 to $20 \%$ polyacrylamide) and subjected to Western blot analysis with $p 53$ and $p 21$ primary antibodies. The reactive bands were revealed and detected with the Odyssey ${ }^{\mathrm{TM}}$ Infrared Imaging System. $\beta$-Actin was used as a loading control for protein samples.

$100 \mu \mathrm{M}$ PRIMA-1 induced the expression of $\mathrm{p} 21^{\text {Waf } 1 / \mathrm{cip}^{1}}$ at 4 hours. However, treatment of these cells with PRIMA-1 in the presence of $20 \mu \mathrm{M}$ PFT $\alpha$ resulted in an inhibition of p21 Waf11 ${ }^{c i p 1}$ expression. No change in the level of p53 protein was observed under these conditions. In contrast, no change in the expression of $\mathrm{p} 21^{\text {Waf1/cip } 1}$ protein was observed when MCF-7 cells (wild-type p53) were treated with PRIMA-1 in the presence of PFT $\alpha$, confirming the specificity of action of PFT $\alpha$ as an inhibitor of p53-dependent transcriptional function. The lack of inhibition of p21 expression in MCF-7 cells after treatment with PFT $\alpha$ suggests that there is p53-independent expression of p21 in these cells or that MCF-7 cells is not sensitive to the dosage of PFT $\alpha$ used in our studies. Furthermore, the data also show that mutant $\mathrm{p} 53$ reactivation by PRIMA-1 results in the transcriptional activation of p53 target genes such as p21Waf1/cip1. However, the exact molecular mechanisms by which this activation occurred are not yet determined. Identification of the molecular targets that are involved in mutation reactivation of p53 by PRIMA-1 is essential for understanding the molecular mechanisms for p53 mutation reactivation and for devising therapeutic strategies aimed at enhancing the use of PRIMA-1 in cancer therapy. It is conceivably possible, for example, that PRIMA-1 affects cellular chaperones resulting in the refolding of mutant p53. In an attempt to identify possible molecular targets involved in mutation reactivation of $\mathrm{p} 53$ by PRIMA-1, we used a functional proteomics approach in which cell lysates were co-immunoprecipitated with DO-1 primary antibody directed against p53 


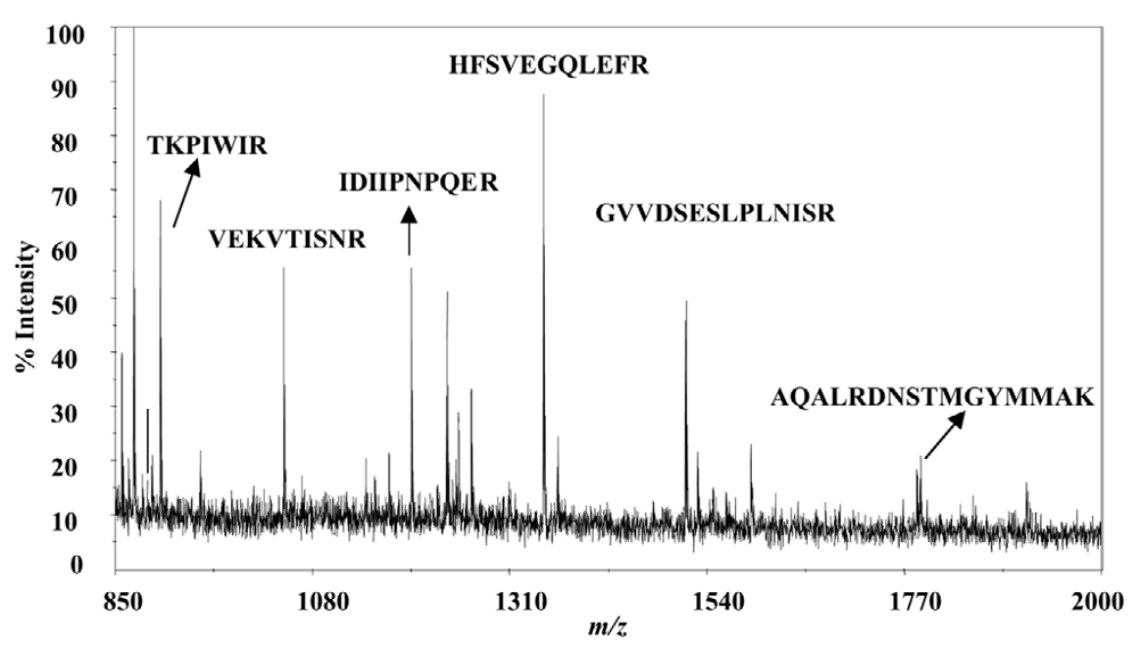

Peptide mass fingerprinting of in-gel tryptic digest of the $90 \mathrm{kDa}$ band generated with a matrix-assisted laser desorption ionization-time-of-flight mass spectrometer. Protein bands indicated by the arrowhead in Fig. 1 were subjected to in-gel digestion and analyzed by mass spectrometry. The tryptic peptides from this band showed the presence of six peptides corresponding to heat shock protein 90 (Hsp90) as one of the proteins that were found in the altered protein-protein interaction pattern of $\mathrm{p} 53$ with and without PRIMA-1 treatment.

after treatment with PRIMA-1 followed by protein partner identification with MALDI-TOF mass spectrometry.

\section{Figure 4}

\section{(a) MDA-231}

IP:
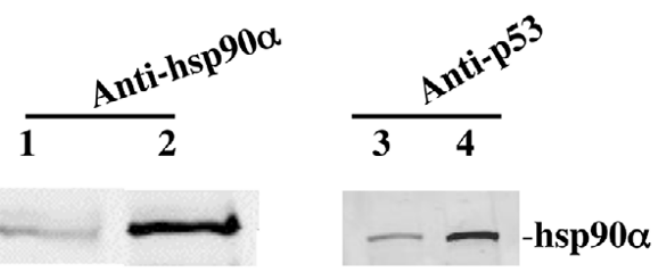

(b)

GI-101A

IP:

p53-

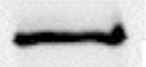

$\operatorname{sp9} 9 \alpha$
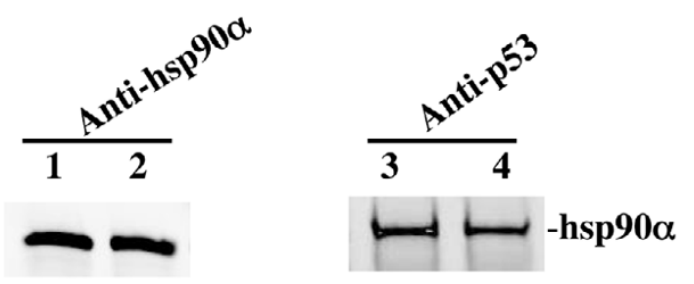

Protein-protein interaction analysis of p53 and the $\alpha$ isoform of heat shock protein $90(\mathrm{Hsp} 90 \alpha)$. (a) MDA-231 cell lysates from untreated cells (lanes 1 and 3 ) and cells treated for 4 hours with $100 \mu \mathrm{M}$ PRIMA1 (lanes 2 and 4) were immunoprecipitated (IP) with anti-Hsp90 $\alpha$ monoclonal antibody and subjected to Western blotting (WB) with anti-p53 (DO-1) monoclonal antibody (lanes 1 and 2) in addition to reciprocal immunoprecipitation with DO-1 and Western blotting with anti-Hsp90 $\alpha$ (lanes 3 and 4). (b) Gl-101A cell lysates from untreated cells (lanes 1 and 3 ) and cells treated for 4 hours with $100 \mu \mathrm{M}$ PRIMA-1 (lanes 2 and 4) were immunoprecipitated with anti-Hsp90 $\alpha$ monoclonal antibody and subjected to Western blotting with anti-p53 (DO-1) monoclonal antibody (lanes 1 and 2) in addition to reciprocal immunoprecipitation with DO-1 and Western blotting with anti-Hsp90 $\alpha$ (lanes 3 and 4).

\section{Identification of Hsp90 as a candidate target for p53 mutation reactivation}

Figure 1 shows a Coomassie blue-stained gel of proteins coimmunoprecipitated with DO-1 antibody from MDA-MB-231 cells (mut p53) after treatment with $100 \mu \mathrm{M}$ PRIMA-1 for 4 hours. We chose to resolve proteins by one-dimensional electrophoresis because we were able to observe clearly and reproducibly the separation of protein mixtures, especially that of proteins smaller than $100 \mathrm{kDa}$. Single bands of polyacrylamide gel slices from SDS-PAGE that are differentially expressed after treatment with PRIMA-1 were excised and subjected to in-gel digestion by trypsin. After digestion, a small portion of the supernatant was removed and analyzed by highaccuracy peptide mass mapping with MALDI. The peptide masses obtained by MALDI analysis were used to search protein databases. We routinely observe peaks that correspond to keratin, presumably resulting from contamination during the handling of gel slices. Such peaks were excluded from our analysis and were occasionally used for internal calibration. Figure 1 focuses on a single band $(90 \mathrm{kDa})$ that is marked by an arrow because it is one of the bands that is distinctly expressed in MDA-MB-231 cells after treatment with PRIMA1 and co-immunoprecipitated with DO-1 monoclonal antibody. The tryptic digests of the excised bands were subjected to mass fingerprinting with the MALDI-TOF mass spectrum as reported previously [26]. Figure 3 illustrates the MALDI mass spectrum acquired from the peptide mixture resulting from ingel digestion of the $90 \mathrm{kDa}$ bands shown in Fig. 1. On average, six peptide masses were identified in this spectrum that agreed with the expected peptide masses within a mass tolerance of $\pm 0.24 \mathrm{Da}$. The peak $\mathrm{m} / \mathrm{z}$ values were used to search the SwissProt Database with the ProFound program. This search resulted in the identification of Hsp90 (Klenow frag- 
ment) with a probability score of 1.0 and $Z$ score of 1.8 , a strong identification of this protein. The sequence coverage of the matched protein candidate (Klenow fragment) was $27 \%$. These results were repeated with multiple co-immunoprecipitation experiments, which all resulted in the identification of $\mathrm{Hsp} 90 \alpha$ as a candidate protein that is differentially expressed after treatment of cells with PRIMA-1.

Because the data collected by peptide mass fingerprinting are sometimes insufficient for the reliable identification of a protein, we further validated and confirmed the identity of Hsp90 protein by immunoblotting analyses. Cells were treated with $100 \mu \mathrm{M}$ PRIMA-1 for 2, 4 or 8 hours, and protein samples from the whole cell extracts (WCE) and nuclear extracts (NE) were Western blotted with antibodies directed against both the $\alpha$ and $\beta$ forms of Hsp90 protein. In mammalian cells there are at least two Hsp90 isoforms, $\mathrm{Hsp} 90 \alpha$ and $\mathrm{Hsp} 90 \beta$, which are encoded by separate genes. The amino acid sequences of human and yeast $\mathrm{Hsp} 90 \alpha$ are $85 \%$ and $90 \%$ homologous to Hsp90 $\beta$, respectively [27]. All known members of the Hsp90 protein family are highly conserved, especially in the amino-terminal and carboxy-terminal regions that contain independent chaperone sites with different substrate specificity $[28,29]$. To confirm the interaction of p53 with $\mathrm{Hsp} 90 \alpha$, we performed a co-immunoprecipitation assay with monoclonal $\mathrm{Hsp} 90 \alpha$ antibody on control cells and PRIMA-1-treated cells and subjected the immunoprecipitated proteins to immunoblotting with monoclonal antibody against p53 protein (DO-1). As shown in Fig. 4, both MDA-231 and Gl-101A cells exhibited interaction of $\mathrm{p} 53$ with $\mathrm{Hsp} 90 \alpha$ protein. The data indicate that p53 interacts with $\mathrm{Hsp} 90 \alpha$ in both breast cancer cells. However, the p53 and $\mathrm{Hsp} 90 \alpha$ protein-protein interaction is different in both cell lines. For example, Gl-101A cells show no noticeable changes in protein-protein interaction after treatment with PRIMA-1 (Fig. 4b), whereas more Hsp $90 \alpha$ is bound to p53 in MDA-231 cells after treatment with PRIMA-1 (Fig. 4a). This may reflect the phenotype of cells as well as differences in p53 mutations and polymorphism [16].

\section{Nuclear translocation of Hsp90 $\alpha$ after treatment with PRIMA-1}

The Western blots in Fig. 5 a show that both isoforms of Hsp90 are expressed in both cell lines, although in different amounts. The $\alpha$-isoform is expressed in greater amounts than the $\beta$-isoform in samples obtained from both WCE and NE. In addition, $\mathrm{Hsp} 90 \alpha$ was detected in the NE of protein samples obtained from both cell lines. The level of Hsp90 $\alpha$ in the NE was increased after treatment of cells with PRIMA-1 for 8 hours. In contrast, the Hsp90 $\beta$ isoform was not detected in the NE of protein samples obtained from either cell line, suggesting that only the $\alpha$ isoform of Hsp90 is translocated to the nucleus after treatment with $100 \mu \mathrm{M}$ PRIMA-1. The exact mechanism(s) for this differential translocation are not clear yet. However, the intracellular localization of $\mathrm{Hsp} 90$ has been investigated under normal and heat-stressed conditions. After heat stress, an increased amount of $\mathrm{Hsp} 90 \alpha$ was detected in the nucleus of cells compared to unstressed cells[30,31]. For nuclear localization to occur, the nuclear localization signal (NLS) is usually required. For Hsp90 $\alpha$, as well as for many other proteins, the nuclear import is recognized by an NLS receptor (a heterodimeric complex) that is composed of importin $\alpha$ and $\beta$ subunits [32-34]. It has been shown that, under in vitro conditions, $\mathrm{Hsp} 90 \alpha$ interacts with importin $\alpha$ [31].

It is also possible that the nuclear transport of $\mathrm{Hsp} 90 \alpha$ after treatment with PRIMA-1 constitutes part of a selective delivery of restored conformation of p53 to the nucleus. The nuclear transport of the wild-type p53 is also known to be dependent on NLS systems [34]. We therefore investigated whether the observed nuclear accumulation of $\mathrm{Hsp} 90 \alpha$ after treatment with PRIMA-1 was correlated with any changes in p53 protein expression and/or localization. Figure $5 b$ shows the nuclear accumulation of p53 after treatment of cells with $100 \mu \mathrm{M}$ PRIMA-1 for 2, 4 or 8 hours. The ratio of the integrated absorbance of p53 bands to that of the actin band was used as an index of protein expression in both WCE and NE. It is clearly shown in Fig. $5 b$ that the levels of p53 protein in the NE are much higher after the treatment of both cell lines with PRIMA1 , especially at 8 hours, indicating that the observed increase of $\mathrm{Hsp} 90 \alpha$ protein levels in the NE (Fig. 5a) is correlated with that of p53 protein nuclear accumulation. We observed no change in the level of p53 protein expression or localization when MCF-7 cells were treated with PRIMA-1 (data not shown). These data therefore suggest that the Hsp90 protein is a binding partner to $\mathrm{p53}$ after its conformational restoration by PRIMA- 1 and that the $\alpha$-isoform is involved in the nuclear accumulation of the active form of p53 protein. The enhanced nuclear translocation of $\mathrm{Hsp} 90 \alpha$ was also investigated with immunocytochemistry. Figure 6 shows that Hsp90 $\alpha$ is selectively localized in the nucleus of MDA-231 breast cancer cells treated with PRIMA-1 for 8 hours.

Many studies showed that the Hsp90 protein has a major role in the stability of p53 protein and in its translocation to the nucleus. King and colleagues [35] reported that the wild-type p53 protein forms a complex with Hsp90 in the presence of Hop and that Hsp90 may assist p53 import into the nucleus. However, the type of Hsp90 isoform that is actually involved in the nuclear translocation of p53 was not mentioned in that study. Chen and Wang [36] recently reported that the stabilization of $\mathrm{p} 53$ conformation after heat shock is associated with its binding to $\mathrm{Hsp} 90$ protein and that the phosphorylation of p53 is dependent on the Ataxia-telangiectasia-mutated protein kinase (ATM)-mediated activation of human checkpoint 2 (ChK2) kinase. Although these studies investigated the role of Hsp90 in regulating p53 stability under stressful conditions (heat shock), the present studies confirmed the association between $\mathrm{Hsp} 90$ and p53 under non-stressful conditions, because there was no increase in $\mathrm{Hsp} 90$ expression in WCE in PRIMA-1-treated cells (Fig. 5b), although a small decrease 

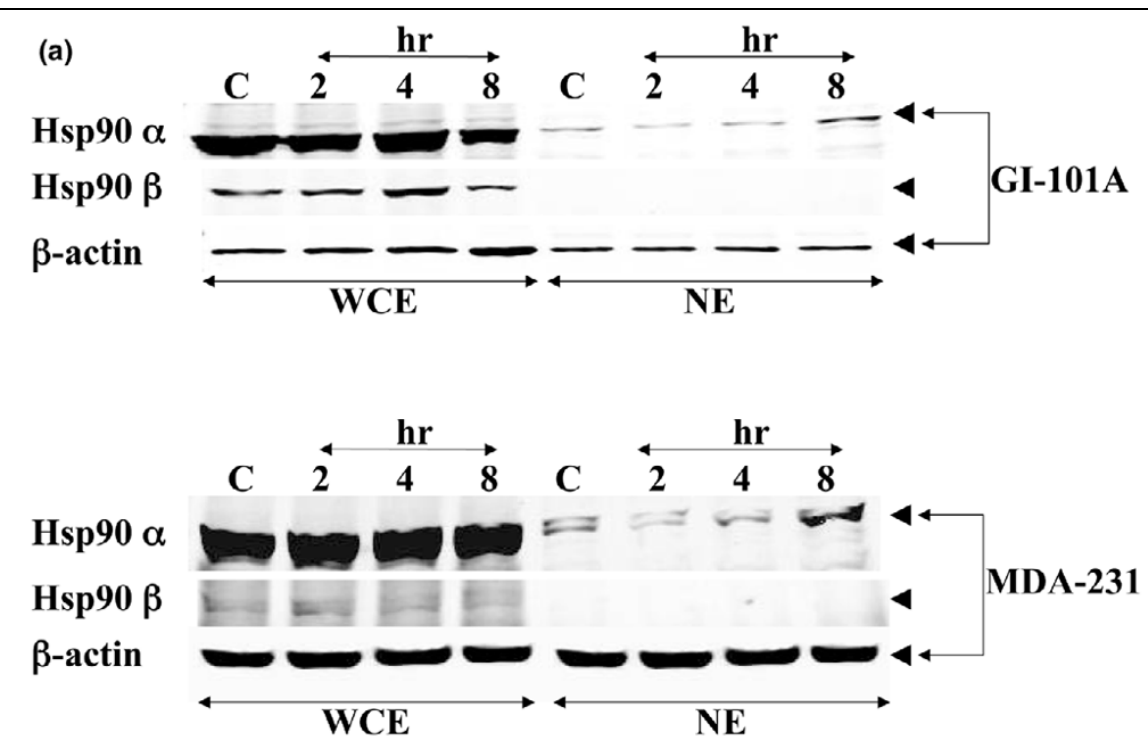

(b)

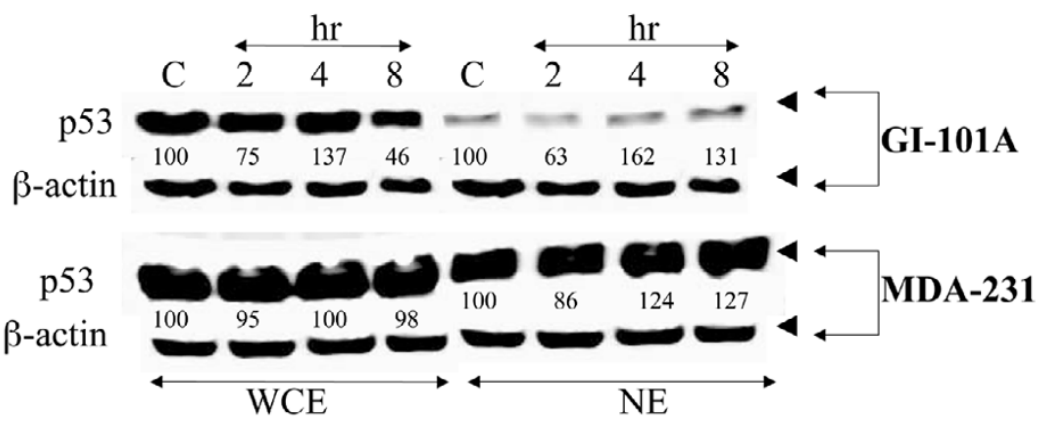

Western blots of heat shock protein 90 (Hsp90) proteins from control and PRIMA-1-treated cells. Cells were treated with $100 \mu \mathrm{M}$ PRIMA-1 for 2, 4 or 8 hours. $20 \mu \mathrm{g}$ of protein samples of cell lysates from the whole cell extracts (WCE) and nuclear extracts (NE) of the control (C) and treated samples were separated by SDS-PAGE ( 4 to $20 \%$ polyacrylamide) and Western blotted with antibodies directed against both the $\alpha$ and $\beta$ isoforms of Hsp90 (a) and against p53 (b). $\beta$-Actin was used as a loading control. The reactive bands were detected with the Odyssey ${ }^{\mathrm{TM}}$ Infrared Imaging System.

in WCE of PRIMA-1-treated samples at 8 hours was concomitant with an increase in nuclear translocation of Hsp90 $\alpha$ in both cell lines.

Recently, Walerych and colleagues [37] reported that Hsp $90 \alpha$ interacts with wild-type p53 protein and that this interaction facilitates the binding of $\mathrm{Hsp} 90 \alpha$ to the $\mathrm{p} 21$ promoter in ATP-dependent manner. Murphy and colleagues [38] showed that PFT $\alpha$ inhibits the p53 signaling after interaction with $\mathrm{Hsp} 90 \alpha$. Thus, both reports $[37,38]$ suggest that the interaction of p53 and $\mathrm{Hsp} 90 \alpha$ enhances the transcriptional transactivation of genes containing p53-binding sites in their promoter region. Our findings can be interpreted as the restoration of the $\mathrm{p} 53-\mathrm{Hsp} 90 \alpha$ interaction by PRIMA-1, enhancing the nuclear translocation of $\mathrm{p} 53-\mathrm{Hsp} 90 \alpha$ and reactivating the transcriptional activity of p53.

\section{Sensitization of breast cancer cells to DNA targeted agents with PRIMA-1}

We next examined whether reactivation of the p53 mutation by PRIMA-1 would enhance the cytotoxicity of DNA-damaging agents such as adriamycin in vitro. Because many studies have shown that p53 mutations are associated with a decreased sensitivity of tumor cells to many chemotherapeutic agents [3-6,39], it seems reasonable that PRIMA-1, which restores p53 transcriptional activity and enhances its nuclear translocation, would increase the sensitivity of these cells to DNA-targeted agents. Figure 7 shows that simultaneous treatment of human breast cancer MDA-231 and Gl-101A cells in vitro with $100 \mu \mathrm{M}$ PRIMA-1 and $0.2 \mu \mathrm{M}$ adriamycin for 24 hours, or sequential treatment with adriamycin for 3 hours followed by PRIMA-1 for 24 hours, significantly enhances the sensitivity of tumor cells to the drug combination compared with the use of each drug alone. On close examination of the percentage of cell survival after drug treatment of MDA-231 
p53
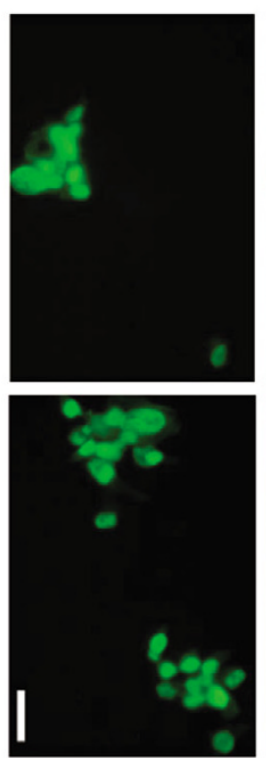

DAPI
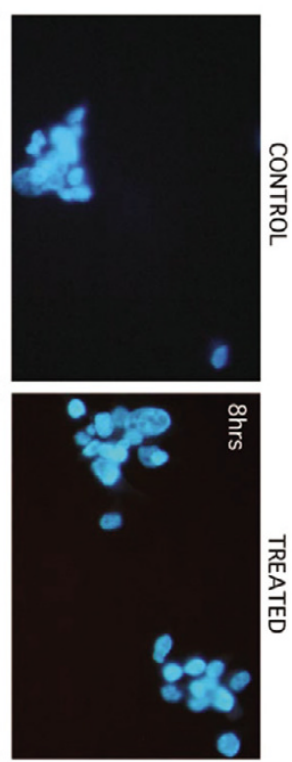

hsp90a
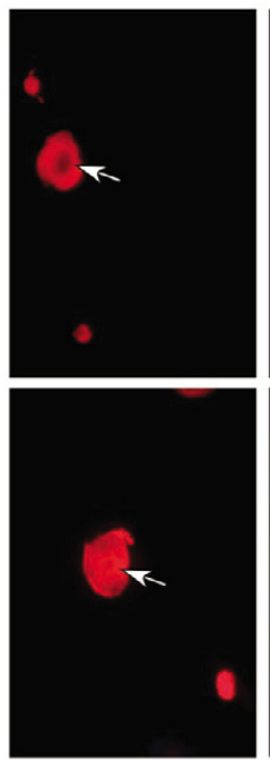

DAPI
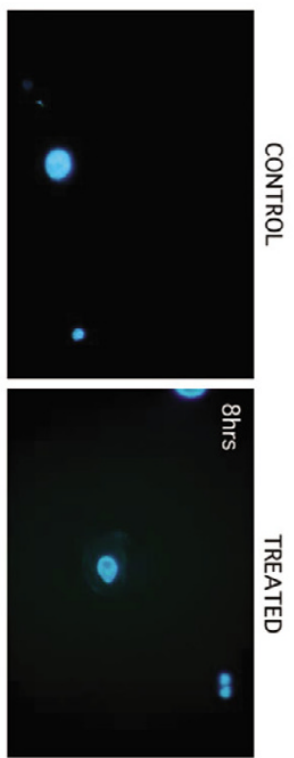

The nuclear localization of the $\alpha$ isoform of heat shock protein $90(\mathrm{Hsp} 90 \alpha)$ is enhanced by treatment of cells with PRIMA-1. MDA-231 cells treated with PRIMA-1 were subjected to nuclear isolation. A fraction of the isolated nuclear pellet was fixed in $4 \%$ paraformaldehyde, permeabilized in $0.1 \%$ Triton X-100 and incubated overnight with anti-p53 and anti-Hsp90 $\alpha$ monoclonal antibodies. Nuclear fractions were then immunostained with a secondary antibody conjugated with Oregon green to detect p53 (green) and a secondary antibody conjugated with Texas red to detect Hsp90 $\alpha$ (red) before detection by fluorescence microscopy. Nuclei were stained with 4',6-diamidino-2-phenylindole (blue). Normal mouse immunoglobulin G was used as a negative control (data not shown). Arrows mark nuclear staining of Hsp90 $\alpha$. Scale bar, $5 \mu \mathrm{m}$.

cells, it is clearly shown that adriamycin treatment for 3 hours (A3) had $95 \%$ cell survival, compared with only $30 \%$ in the presence of PRIMA-1 (A3P24). Treatment of these cells for 24 hours with PRIMA-1 alone produced $75 \%$ cell survival. These data suggest that PRIMA-1 enhances adriamycin efficacy and that the drug combination, in this case, is synergistic or supraadditive. Preliminary evidence from our laboratory indicates that the drug combination is also synergistic on a panel of breast cancer cell lines (Tao Wang and S.S.D., unpublished work).

\section{Conclusion}

This study illustrates the use of a functional proteomics approach to identify target molecules that are associated with the reactivation of a p53 mutation by PRIMA-1. Our approach has identified $\mathrm{Hsp} 90 \alpha$ as a partner protein that is associated, in part, with the restoration of p53 transcriptional transactivation function by PRIMA-1. We also showed that the $\alpha$ isoform of $\mathrm{Hsp} 90$ protein is associated with the nuclear translocation of p53 protein after treatment of breast tumor cells with PRIMA-1. Our results that PFT $\alpha$ inhibits the induction of p21 expression after treatment with PRIMA-1, and the recent work of Murphy and colleagues [38] indicating that PFT $\alpha$ inhibits the signaling of p53-mediated gene transcription, strongly suggest that PRIMA-1 facilitates the interaction of $\mathrm{Hsp} 90 \alpha$ and the restoration of mutant p53 to wild type followed by the

\section{Figure 7}

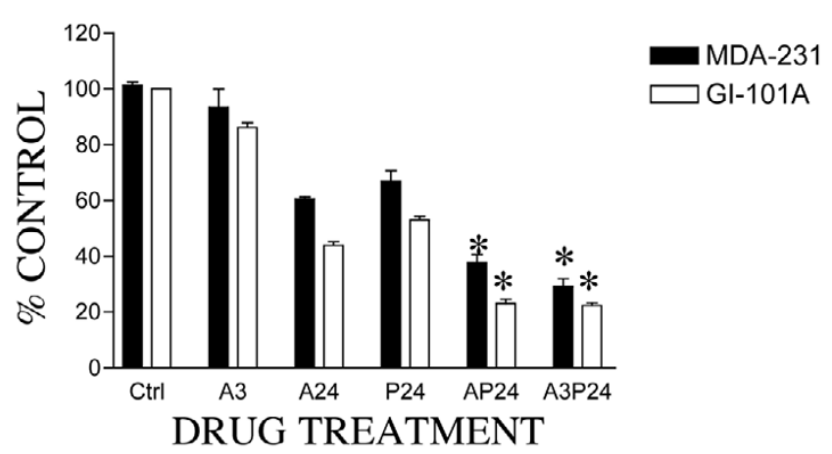

Combination and sequential exposure of cells to PRIMA-1 and adriamycin. Exponentially growing MDA-MB-231 or Gl-101A cells were seeded in $10 \%$ serum-supplemented RPMI- 1640 medium at $10^{4}$ cells per well. After 24 hours, cells were treated with $100 \mu \mathrm{M}$ PRIMA-1 for 24 hours (P24), $0.2 \mu \mathrm{M}$ adriamycin for 3 hours (A3) or 24 hours (A24), and a combination of PRIMA-1 plus adriamycin for 24 hours (AP24) or adriamycin for 3 hours followed by PRIMA-1 for 24 hours (A3P24). After drug treatment, the cells were reincubated in drug-free medium for a further 3 days and cell survival was determined with the crystal violet assay. Results are means \pm SD for quadruplicate determinations $(\mathrm{SD}<10 \%)$ representative of two to four independent experiments; $P<0.01$. 
translocation of both proteins into the nucleus. This may result in the transactivation of genes containing p53-binding sites as reported by Walerych and colleagues [37].

\section{Competing interests}

The author(s) declare that they have no competing interests.

\section{Authors' contributions}

AR performed cell culture studies, immunoblotting and immunoprecipitation, subcellular fractionation and immunocytochemistry, and participated in drafting the manuscript. MSC participated in immunoblotting studies. XT performed out ingel enzymatic digestion of separated bands, and mass spectrometry. JEB participated in the protein identification and sequencing. YP participated in the design of the study and drafting of the manuscript. SSD conceived the study, participated in the design of its study and coordination and drafted the manuscript. All authors read and approved the final manuscript.

\section{Acknowledgements}

We thank Dr Heiko T Jansen (Washington State University, Pullman, WA) for help with the immunocytochemistry studies. This work is supported in part by grant no. BCTR0402398 to SSD from The Susan G Komen Foundation for Breast Cancer Research.

\section{References}

1. Berns EM, van Staveren IL, Look MP, Smid M, Klijn JG, Foekens JA: Mutations in residues of TPp53 that directly contact DNA predict poor outcome in human primary breast cancer. $\mathrm{Br} J$ Cancer 1998, 77:1130-1136.

2. Weinstein JN, Myers TG, O'Connor PM, Friend SH, Fornace AJ, Kohn KW, Fojo J, Bates SE, Rubinstein LV, Anderson NL, et al.: An information-intensive approach to the molecular pharmacology of cancer. Science 1997, 275:343-349.

3. Jones CB, Clements MK, Wasi S, Daoud SS: Sensitivity to camptothecin of human breast carcinoma and normal endothelial cells. Cancer Chemother Pharmacol 1997, 40:475-483.

4. Goldwasser F, Shimizu T, Jackman J, Hoki Y, O'Connor PM, Kohn $\mathrm{KW}$, Pommier Y: Correlations between S and G2 arrest and the cytotoxicity of camptothecin in human colon carcinoma cells. Cancer Res 1996, 56:4430-4437.

5. Fan S, El-Deiry WS, Bae I, Freeman J, Jondle D, Bhatia K, Fornace AJ, Magrath I, Kohn KW, O'Connor PM: p53 gene mutations are associated with decreased sensitivity of human lymphoma cells to DNA damaging agents. Cancer Res 1994, 54:5824-5830

6. Iwadate $\mathrm{Y}$, Fujimoto $\mathrm{S}$, Tagawa M, Namba H, Sueyoshi K, Hirose M, Sakiyama S: Association of p53 gene mutation with decreased chemosensitivity in human malignant gliomas. Int J Cancer 1996, 69:236-240.

7. Daoud SS, Munson PJ, Reinhold W, Young L, Prabhu V, Yu Q, LaRose J, Kohn KW, Weinstein JN, Pommier Y: Impact of p53 knockout and topotecan treatment on gene expression profiles in human colon carcinoma cells: a pharmacogenomic study. Cancer Res 2003, 63:2782-2793.

8. Lai H, Lin L, Nadji M, Lai S, Trapido E, Meng L: Mutations in the p53 tumor suppressor gene and early onset breast cancer. Cancer Biol Ther 2002, 1:31-36.

9. Blaszyk H, Hartmann A, Cunningham JM, Schaid D, Wold LE, Kovach JS, Sommer SS: A prospective trial of Midwest breast cancer patients: a p53 gene mutation is the most important predictor of adverse outcome. Int J Cancer 2000, 89:32-39.

10. Bull SB, Ozcelik H, Pinnaduwage D, Blackstein ME, Sutherland DA, Pritchard KI, Tzontcheva AT, Sidlofsky S, Hanna WM, Qizilbash $\mathrm{AH}$, et al:: The combination of p53 mutation and neu/
erbB2 amplification is associated with poor survival in nodenegative breast cancer. J Clin Oncol 2004, 22:86-96.

11. Hupp TR, Sparks A, Lane DP: Small peptides activate the latent sequence-specific DNA binding function of p53. Cell 1995, 83:237-245.

12. Issaeva N, Friedler A, Bozko P, Wiman KG, Fersht AR, Selivanova G: Rescue of mutants of the tumor suppressor p53 in cancer cells by a designed peptide. Proc Natl Acad Sci USA 2003, 100:13303-13307.

13. Chen L, Lu W, Agarwal S, Zhou W, Zhang R, Chen J: Ubiquitous induction of p53 in tumor cells by antisense inhibition of MDM2 expression. Mol Med 1999, 5:21-34.

14. Foster BA, Coffey HA, Morin MJ, Rastinejad F: Pharmacological rescue of mutant p53 conformation and function. Science 1999, 286:2507-2510.

15. Bykov VJN, Selivanova G, Wiman KG: Small molecules that reactivate mutant p53. Eur J Cancer 2003, 39:1828-1834.

16. Bykov VJN, Issaeva N, Shilov A, Hultcrantz M, Pugacheva E, Chumakov P, Bergman J, Wiman K, Selivanova G: Restoration of the tumor suppressor function to mutant $\mathrm{p} 53$ by a low-molecularweight compound. Nat Med 2002, 8:282-288.

17. Chipuk JE, Maurer U, Green DR, Schuler M: Pharmacologic activation of p53 elicits Bax-dependent apoptosis in the absence of transcription. Cancer Cell 2003, 4:371-381.

18. Rehman A, Chahal MS, Pommier Y, Daoud SS: PRIMA-1 restores the p21 transactivation by tumor suppressor p53 in breast cancer cells. Proc AACR 2003, 44:4592.

19. Clements $M K$, Jones $C B$, Cumming M, Daoud SS: Antiangiogenic potential of camptothecin and topotecan. Cancer Chemother Pharmacol 1999, 44:411-416.

20. ProFound program [http://prowl.rockefeller.edu/profound bin/ WebProFound.exe]

21. Jansen HT, Cutter C, Hardy S, Lehman MN, Goodman RL: Seasonal plasticity within the gonadotropin-releasing hormone (GnRH) system of the ewe: changes in identified GnRH inputs and glial association. Endocrinology 2003, 144:3663-3676.

22. El-Deiry WS, Tokino T, Velculescu VE, Levy DB, Parson R, Trent $\mathrm{JM}$, Lin D, Mercer WE, Kinzler KW, Vogelstein B: WAF1, a potential mediator of p53 tumor suppression. Cell 1993, 75:817-825.

23. Akashi M, Osawa $Y$, Koeffler HP, Hachiya M: p21WAF1 expression by an activator of protein kinase $C$ is regulated mainly at the post-transcriptional level in cells lacking p53: important role of RNA stabilization. Biochem J 1999, 337:607-616.

24. Zeng YX, El-Deiry WS: Regulation of p21WAF1/CIP1 gene expression by p53-independent pathways. Oncogene 1996, 12:1557-1564.

25. Komarov PG, Komarova EA, Kondratov RV, Christov-Tselkov K, Coon JS, Chernov MV, Gudkov AV: A chemical inhibitor of p53 that protects mice from the side effects of cancer therapy. Science 1999, 285:1733-1737.

26. Goodlett DR, Bruce JE, Anderson GA, Rist B, Pasa-Tolic L, Fiehn $\mathrm{O}$, Smith RD, Aebersold R: Protein identification with a single accurate mass of a cysteine-containing peptide and constrained database searching. Anal Chem 2000, 72:1112-1118.

27. Nemoto T, Sato N: Oligomeric forms of the $90-\mathrm{kDa}$ heat shock protein. Biochem J 1998, 330:989-995.

28. Yamada S, Ono T, Mizuno A, Nemoto TK: A hydrophobic segment within the $C$-terminal domain is essential for both client binding and dimer formation of the HSP90-family molecular chaperone. Eur J Biochem 2003, 270:146-154.

29. Matsumoto $S$, Tanaka E, Nemoto TK, Ono T, Takagi T, Imai J, Kimura Y, Yahara I, Kobayakawa T, Ayuse T, et al.: Interaction between the $\mathrm{N}$-terminal and middle regions is essential for the in vivo function of HSP90 molecular chaperone. J Biol Chem 2002, 277:34959-34966.

30. Akner G, Mossberg K, Sundqvist KG, Gustafsson JA, Wikström AC: Evidence for reversible, non-microtubule and non-microfilament-dependent nuclear translocation of Hsp90 after heat shock in human fibroblasts. Eur J Cell Biol 1992, 58:356-364.

31. Langer T, Rosmus S, Fasold H: Intracellular localization of the 90 kDA heat shock protein (HSP90 $\alpha$ ) determined by expression of a EGFP-HSP90 $\alpha$-fusion protein in unstressed and heat stressed 3T3 cells. Cell Biol Int 2003, 27:47-52.

32. Görlich D, Kutay U: Transport between the cell nucleus and the cytoplasm. Annu Rev Cell Dev Biol 1999, 15:607-660. 
33. Longshaw VM, Chapple JP, Balda MS, Cheetham ME, Blatch GL: Nuclear translocation of the Hsp70/Hsp90 organizing protein mSTI1 is regulated by cell cycle kinases. J Cell Sci 2004, 117:701-710.

34. Febbro M, Henderson BR: Regulation of tumor suppressors by nuclear-cytoplasmic shuttling. Exp Cell Res 2003, 282:59-69.

35. King FW, Wawrzynow A, Höhfeld J, Zylicz M: Co-chaperones Bag-1, Hop and Hsp40 regulate $\mathrm{Hsc70}$ and $\mathrm{Hsp} 90$ interactions with wild type or mutant p53. EMBO J 2001, 20:6297-6305.

36. Chen J, Wang C: Phosphorylation and hsp90 binding mediate heat shock stabilization of p53. J Biol Chem 2003, 278:2066-2071.

37. Walerych D, Kudla G, Gutkowska M, Wawrzynow B, Muller L, King FW, Helwak A, Boros J, Zylicz A, Zylicz M: Hsp90 chaperones wild-type p53 tumor suppressor protein. J Biol Chem 2004, 279:48836-48845.

38. Murphy PJ, Galigniana MD, Morishima Y, Harrell JM, Kwok RP, Ljungman $M$, Pratt $W$ : Pifithrin- $\alpha$ inhibits p53 signaling after interaction of the tumor suppressor protein with hsp90 and its nuclear translocation. J Biol Chem 2004, 279:30195-30201.

39. Aas T, Borresen AL, Geisler S, Smith-Sorensen B, Johnsen H, Varhaug JE, Akslen LA, Lonning PE: Specific p53 mutations are associated with de novo resistance to doxorubicin in breast cancer patients. Nat Med 1996, 2:811-814. 